\title{
DISCUSSION - SESSIONS IV \& V
}

Principal discussants: Austin Long, University of Arizona, Mike Baillie, Queen's University of Belfast, Wim Mook, University of Groningen, Doug Harkness, NERC, Henry Polach, Australian National University, Jon Pilcher, Queen's University of Belfast, Mebus Geyh, Hannover, Roberto Gonfiantini, IAEA, Mark Pollard, College of Cardiff, Marian Scott, University of Glasgow

A point for concern was that none of the participants in the study, nor present at the workshop, came from commercial labs. Participants viewed it as important that future studies should include such labs.

We discussed the selection of samples in the IAEA proposals and various reasons for the choice of materials, which were:

1. Their age should be spread corresponding to ${ }^{14} \mathrm{C}$ needs and should range from modern to background.

2. Samples must be available in bulk.

3. Organizers must be able to guarantee homogeneity of the material. The IAEA reference materials were then discussed in greater detail:

1. Cellulose. Cellulose can be homogeneously prepared and is easy to transport.

2. Charcoal. The process of production must guarantee homogeneity.

3. Marble. Particle size is critical, because of the possibility of atmospheric contamination.

The IAEA reference samples will require no further pretreatment and homogeneity will be rigorously tested. Further reference samples would include oxalic acid at background activity. The reason for such a sample is its use as a modern reference standard and, hence, its familiarity to the community. An additional background sample, carbonate, would also be available.

The major benefits of the IAEA offer to the ${ }^{14} \mathrm{C}$ community are:

1. Known-age samples would be well calibrated and homogeneous.

2. New labs could easily obtain the materials at low cost and quickly assess their performance.

The IAEA representatives, Gonfiantini and Rozanski, assured the participants that the cost of the samples would be low and could be paid in local currency or charged, where appropriate, to an IAEA project. Another idea was to have a very old sample say, 20,000 to 30,000 years old, in addition to a background sample. But the consensus was that there would be no basic difference for a lab between such a sample and a true background sample.

The continuing discussion centered around the timetable for the IAEA proposals. A deadline of October $1990^{1}$ was set for the completion of the first intercalibration. The results will be published in RADIOCARBON after they are discussed at a meeting to be held in Vienna. Attendance at the meeting will be completely open. Quality control of a laboratory lies beyond the scope of the IAEA, the difficulties, in this instance, being the non-uniformity of sample treatment.

Participants further discussed the choice of sample types, eg, some felt benzene is appropriate, but major shipping and storage problems preclude this choice.

In summary, the consensus view was that the IAEA scheme should be regarded as a form of self-help: labs should not be anonymous and any lab could request samples when and if required. As for encouraging participation in such schemes, within the UK, the view is that the proposal for quality assurance is made by and for the ${ }^{14} \mathrm{C}$ community. Funding agencies should, of course, consider the proposals; one possibility might be that only labs taking part in such exercises should be funded. Lab performances should be subject to considerable scrutiny in the future.

${ }^{1}$ Note added in proof: the first deadline of October 1990 has been moved up to early 1991. 


\section{Discussion}

We announced that the proceedings and discussions of this Workshop will be published in RADIOCARBON in Volume 32, No. 3, which will appear in late 1990.

The ${ }^{14} \mathrm{C}$ community firmly believe that they must convince users of the quality of dating and its improvement. To this end, we discussed a number of proposals presented earlier in the week:

1 . We discussed the provision of reference samples by the IAEA for laboratory control of internal stability of measurements. Discussants thought that this offer should be accepted and that all future IAEA meetings should be open to all.

2. Additional and complementary proposals are summarized as follows:

a. Austin Long presented an outline of a Quality Control scheme, which should be worked out in detail and sent to all labs for comment. Dr Long will present the final version in these Proceedings, as the recommended procedure to the ${ }^{14} \mathrm{C}$ community.

b. The Quality Control system will include assay of reference samples on a regular basis. These will be available from IAEA, but labs will still use in-house standards, against which the IAEA samples should be calibrated. IAEA reference materials will be cellulose, charcoal, wood, carbonate travertine and marble. Laboratories will use these materials to control internal stability of measurements. The samples will be checked for homogeneity and the first intercalibration will be almost blind. Samples will be distributed, starting in February ${ }^{2} 1990$, to all those who have requested them from IAEA. Labs do not need to take all the samples on offer. Laboratories should submit results to IAEA by July ${ }^{2} 1990$. IAEA will then compile the results and send them to all participants. Labs need not return results. They may also wait for publication of the results in RADIOCARBON. In addition, IAEA will host a meeting in Vienna and present a final report.

c. The ${ }^{14} \mathrm{C}$ community should continue further blind intercomparison tests, hopefully under the direction of the Glasgow group. These further tests might coincide with ${ }^{14} \mathrm{C}$ meetings. This procedure ensures objective verification of improvements.

Some participants suggested including peat and marine sediments in the IAEA reference samples. This will be considered and suitable samples sought.

The IAEA schedule outlined above is very tight and will be difficult to meet. Thus, reference samples should be submitted as soon as possible. If the first deadline cannot be met, samples should still be sent for use in future intercalibration exercises. Those submitting the samples to IAEA should test samples for homogeneity, then package and ship them to Vienna. It is extremely important that these initiatives be fully and widely advertised to ensure that as many labs as possible have the opportunity to participate. Announcements have already appeared in RADIOCARBON.

Discussions then centered on the third part of the proposals, namely, the blind intercomparisons.

First, the organizers (Marian Scott, Doug Harkness, Murdoch Baxter, Gordon Cook and Tom Aitchison) will ensure continuation of the procedures which the Glasgow group have established during the previous two studies. The main objective will be self-help for ${ }^{14} \mathrm{C}$ labs. The organizers will air the question of anonymity and encourage openness. However, they would not enforce anonymity.

The UK will fund this further work, thus requiring no costs to participants. ${ }^{3}$ The preliminary proposals follow:

${ }^{2}$ Note added in proof: now $\sim$ May 1990 and December 1990, respectively

${ }^{3}$ Note added in proof: SERC and NERC have agreed to provide a total of $£ 40,000$ to fund this part of the proposals. 
- The tests would operate regularly, every 2 to 3 years. However, it is unrealistic to undertake the next trial before the 14th International Radiocarbon Conference in Arizona, in 1991.

- The samples will include dendro-dated wood.

- Participants will receive a report on the results within four months of completion.

- Labs encountering problems will be able to seek help from peer groups within the ${ }^{14} \mathrm{C}$ community.

These proposals were generally acceptable and all agreed upon the importance of contact among laboratories.

A final point concerned the timing of the next trial - sufficient time for calibration of the international standards should be allowed to ensure that labs are not overloaded. 